\title{
MEDIAÇÃO DA INFORMAÇÃO E A PROTEÇÃO DA PRIVACIDADE E DE DADOS SENSÍVEIS POR BIBLIOTECÁRIOS
}

\section{MEDIATION OF INFORMATION AND THE PROTECTION OF PRIVACY AND SENSITIVE DATA BY LIBRARIANS}

\author{
Richele Grenge Vignolia \\ Wilson Veronez Júnior ${ }^{b}$ \\ Anahi Rocha Silva ${ }^{\mathrm{c}}$ \\ Silvana Drumond Monteiro ${ }^{d}$
}

\begin{abstract}
RESUMO
Introdução: Destaca o papel do bibliotecário no resguardo e sigilo de informações que não podem, não devem ou que não necessitam ser mediadas. Para isso, contextualiza a mediação da informação e apresenta ambiências legais, balizadas na Constituição Federal do Brasil, da Lei de Acesso à Informação, da Lei de Proteção de Dados Pessoais, e ambiências éticas com fulcro no Código de Ética e Deontologia do Bibliotecário no Brasil e no Código de Ética da American Library Association, na precisão e observância de condutas necessárias para não mediar dados ou informações sigilosas e sensíveis de usuários. Objetivo: discutir a respeito dos dados sensíveis na mediação da informação, seja de forma implícita (no processamento técnico da informação) ou na explícita (no atendimento direto a usuários), e no acesso a dados sensíveis de usuários em unidades de informação. Metodologia: Como procedimento metodológico, trata-se de uma pesquisa bibliográfica com abordagem qualitativa. Resultados: Constata-se que dados sensíveis não devem ser divulgados e que por isso, nem toda informação é passível de compartilhamento e mediação. Conclusões: Espera-se contribuir com novas pesquisas e discussões acerca da temática e principalmente com outros estudos nos construtos da literatura da mediação da informação aliada aos dados sensíveis.
\end{abstract}

Descritores: Descritores: Mediação da informação. Privacidade na Mediação da Informação. Dados Sensíveis. Dados Sensíveis na Mediação da Informação. Ética e Mediação da Informação.

\footnotetext{
a Doutoranda do Programa de Pós-Graduação em Ciência da Informação da Universidade Estadual Paulista (PPGCI/UNESP). E-mail: rivignoli@gmail.com.

b Mestrando do Programa de Pós-Graduação em Ciência da Informação da Universidade Estadual Paulista (PPGCI/UNESP). E-mail: veronezw@gmail.com.

c Doutoranda do Programa de Pós-Graduação em Ciência da Informação da Universidade Estadual Paulista (PPGCI/UNESP). E-mail: anahiadv@yahoo.com.br.

d Doutora em Comunicação e Semióticaem pela Pontifícia Universidade Católica de São Paulo (PUC-SP). Docente no Departamento de Ciência da Informação da Universidade Estadual de Londrina (UEL). E-mail: silvanadrumond@gmail.com.
} 


\section{INTRODUÇÃO}

Em 1992, Joana Coeli Ribeiro Garcia, professora do Departamento de Biblioteconomia e Documentação da Universidade Federal da Paraíba (UFPB), por meio de seu artigo "Bibliotecário: informar tudo a todos?" levantou relevantes questionamentos: "[...] todas as informações podem ser do conhecimento de todos? Existem informações sigilosas? Em caso afirmativo, como distinguir o que representa o todos para este tipo de informação?" (GARCIA, 1992, p. 50). A resposta para os questionamentos de Garcia (1992) é o que se pretende discutir neste trabalho.

A literatura científica que versa sobre mediação da informação costuma evidenciar e incentivar a mediação plena da informação por profissionais da informação, como o bibliotecário. Entretanto, informações sigilosas e privadas não devem e/ou não podem ser mediadas, divulgadas, compartilhadas. Os dados sensíveis, tidos como informações inerentes e exclusivas à vida privada de pessoas físicas e jurídicas (VIGNOLI; VECHIATO, 2019), e a objetos como documentos, patentes e outros (AUSTRALIAN NATIONAL DATA SERVICE ANDS, 2019) são constituídos por conteúdos que não devem ser divulgados, seja por motivos individuais ou coletivos, éticos ou legais.

Nessa tangente, o objetivo desta pesquisa é discutir a respeito dos dados sensíveis na mediação da informação, seja de forma implícita (no processamento técnico da informação), ou na explícita (no atendimento direto a usuários), seja no acesso a dados sensíveis de usuários em unidades de informação. A pesquisa apresenta panorama de conteúdos que não devem ser divulgados na mediação da informação, assim como demonstra dispositivos éticos e legais aos quais o bibliotecário precisa conhecer para tratar dados sensíveis em sua rotina de trabalho.

A mediação da informação enquanto conceito e prática evoluiu e fez sobrepor sua emancipação como disciplina e com isso, outras atribuições e significados Ihe foram conferidos. É o que se pode encontrar no ponto de vista de Almeida Júnior $(2008,2009)$ que defende a mediação como o próprio objeto de estudo da Ciência da Informação, além de sua capacidade de interferência 
no usuário. Silva (2015) indica em suas reflexões acerca do conceito de mediação da informação, que a mediação é substrato indiscutível para construção social do conhecimento. Para Gomes (2014, 2019), a mediação da informação é produtora de conhecimento e protagonismo social, além de possuir dimensões múltiplas como a dialógica, estética, formativa, ética e política. No entanto, nem toda informação é igual e nem toda informação é pública, devendo o profissional da informação, em qualquer ambiente, sobretudo no ciberespaço, conhecer mecanismos de privacidade e proteção aos dados sensíveis dos usuários.

O estudo utiliza de pesquisa bibliográfica e abordagem qualitativa. Para contextualizar a mediação da informação e direcionar as discussões pretendidas, foram realizadas buscas bibliográficas no Portal de Periódicos da Capes, na Base de Dados Referencial de Artigos de Periódicos em Ciência da Informação (BRAPCl) e no Google Scholar com os termos: "mediação da informação e dados sensíveis", "ética e mediação da informação", "mediação da informação e proteção de privacidade." O catálogo de leis do Planalto Central formou a base para a recuperação da legislação utilizada na pesquisa. O Código de ética da American Library Association (ALA)/2008 e o Código de Ética e Deontologia do Bibliotecário/2018 foram utilizados na evidência dos aspectos éticos que envolvem o fazer o bibliotecário. Espera-se contribuir com a literatura científica da Ciência da Informação no que tange à mediação da informação e em especial, os dados sensíveis que não devem e não podem ser disseminados.

\section{A MEDIAÇÃO DA INFORMAÇÃO}

De acordo com Houaiss e Villar (2001) e Russ (2003), a palavra mediação é derivada do termo em latim mediatio. Portanto, mediato significa aquilo que: "[...] se têm por intermédio de um intermediário, indireto; por exemplo, conhecimento mediato é aquele que se obtém de maneira indireta." (JAPIASSÚ; MARCONDES, 1998, p. 177). Visto de outra maneira, a mediação só é possível quando há um intermediário que medeia algo com outras partes, como a informação. 
Na Filosofia, a mediação é estabelecida como uma ação criativa, a qual perpassa o processo do início ao fim. Para Russ (2003, p. 180), mediação indica a "[...] ação de dividir em dois, estar no meio." Com uma visão sintética, porém objetiva, a autora esclarece que a mediação propicia estar entre duas partes, dois lados, ou, entre duas pessoas. Pode-se dizer que é neste momento, entre e para algo, ou alguém, que ocorre a mediação. É necessário intermediar para mediar; servir de intermédio. Na Psicologia, a mediação deve ser um espaço entre os participantes, em que o mediador deve ser colaborador desse processo possibilitando que as partes assumam uma posição de protagonistas na dissolução de seus conflitos e que possam refletir e gerar soluções para suas controvérsias (LIMA et al., 2017). Na Educação, o pesquisador russo Vygotsky relaciona a mediação é o processo que caracteriza a relação do sujeito com o mundo e com outros sujeitos. Nesse sentido, a mediação na concepção de Vygotsky é decorrente do conjunto: I - instrumentos, S - Sujeito - e O - Objeto, esquema que explica a mediação como um elemento central, pois é nesse processo que as funções psicológicas superiores típicas dos seres humanos se desenvolvem para a aprendizagem (BERNI, 2006). A Semiótica peirceana não utiliza o termo representação para a ação de interpretação do signo, mas, mediação, uma vez que é um processo relacional triádico mediado pelo signo na mente do intérprete. Em outras palavras, o signo tem uma função ontologicamente mediadora entre o objeto e seu interpretante (SANTAELLA, 2004).

$\mathrm{Na}$ Ciência da Informação, a mediação recebe a nomenclatura de mediação da informação, temática que pode ter seus estudos iniciados desde 1935, quando o escritor e filósofo espanhol José Ortega Y Gasset (1883-1955) anunciou, por meio de sua palestra Misión del bibliotecario realizada durante II Congresso Internacional de Bibliotecários da International Federation of Library Associations and Institutions (IFLA), que cabe ao bibliotecário a responsabilidade em ser um filtro entre os livros e usuários, ou seja, um intermediário - um mediador. De acordo com Sánchez Lambás (2005, p. [10]), Ortega Y Gasset também pronunciou que: "El bibliotecário es um intermediário activo entre los usuarios y los recursos. Es indispensable su formación profesional y permanente 
para que pueda oferecer servicios adecuados [...]" o que confirma a função do bibliotecário como mediador da informação

Freire e Freire (2014) indicam que o primeiro artigo publicado acerca da mediação da informação no Brasil, aconteceu em 1980 na antiga Revista da Escola de Biblioteconomia da Universidade Federal de Minas Gerais (UFMG). Outras vertentes relatam que a mediação da informação fora engendrada cientificamente na década de 1990. Denominada como uma espécie de campo com um vácuo teórico, Belluzzo, Santos e Almeida Júnior (2014) explicam que em seu surgimento, não havia propostas teóricas específicas para essa prática, nem tampouco modelos ou metodologias voltadas para o atendimento de usuários. Naquele momento, as práticas voltadas ao que seria a mediação da informação foram destinadas ao serviço de referência e informação. Para os autores, a mediação da informação passou então, a priorizar o atendimento aos usuários e a se ocupar com o seu relacionamento com os equipamentos informacionais existentes (BELLUZZO; SANTOS; ALMEIDA JÚNIOR, 2014).

Também para Bortolin e Cervantes (2014), os primeiros estudos acerca da mediação da informação e suas diversas nuances foram publicados no Brasil na década de 1990 e mais precisamente em 1992. Entre alguns especialistas do assunto, no contexto brasileiro, estão o pesquisador e professor Oswaldo F. de Almeida Júnior, que inicia debates a respeito da temática em 2001 por meio do projeto de pesquisa "A Mediação da Informação: norteadora do fazer bibliotecário." Para Almeida Júnior (2009), a mediação da informação é o próprio objeto da Ciência da Informação. Nesta suposição, o objeto de estudo da Ciência da Informação não seria mais e somente a informação registrada, mas a própria mediação da informação, a ação de mediar a informação.

Almeida Júnior (2009, p. 25) define a mediação da informação como:

Toda ação de interferência - realizada em um processo, por um profissional da informação e na ambiência de equipamentos informacionais -, direta ou indireta; consciente ou inconsciente; singular ou plural; individual ou coletiva; visando a apropriação de informação que satisfaça, parcialmente e de maneira momentânea, uma necessidade informacional, gerando conflitos e novas necessidades informacionais. 
Com base na conceituação do autor, a capacidade da mediação da informação em gerar conflitos significa que a informação não dissolve dúvidas ou incertezas, ela as cria. Nesse pressuposto, quanto mais informação, mais dúvidas são despertadas e mais informação são necessárias. A informação pode gerar a reconstrução do conhecimento (ou nova informação) no usuário, num processo ininterrupto, isso porque é um processo semiótico, ou seja, um signo para ser interpretado gera outro, em um continuum semiótico.

Para o pesquisador Jonathas Luiz Carvalho Silva (2015, p. 106, grifo nosso), que coaduna com Almeida Júnior $(2008,2009)$ a respeito da mediação como interferência e na apropriação da informação que contemple as necessidades dos usuários, a mediação da informação se apresenta como:

\section{[...] um conjunto de práticas construtivas de intervenções e interferências regidas por intencionalidades, normas/regras, correntes teórico-ideológicas e crenças concebidas pelo profissional da informação em interação com os usuários no âmbito de suas realidades cotidianas e experienciais, indicando procedimentos singulares, coletivos e/ou plurais de acesso e uso da informação, estimulando à apreensão e apropriação para satisfação de necessidades de informação.}

Silva (2015) propõe que a mediação da informação se desenvolva em relação triádica que envolve: a) centros de informação (locais em que a informação está vinculada, armazenada); b) com o bibliotecário e/ou profissionais da informação; c) para quem a mediação se refere: os usuários. Visto de outra forma, para que a ação mediadora (termo de GOMES, 2014, 2019) se concretize na Ciência da Informação, é necessário: um local/instituição mantenedora de informação em seus diversos suportes e mídias + o bibliotecário ou profissional da informação + o(s) usuário(s). Essa equação somatiza-se em: 1) o objeto a ser mediado; 2) por quem o objeto é mediado e 3) para quem o objetivo é mediado, ou o que, por quem e para quem.

Para Silva (2015), a mediação da informação é resumida também por três palavras que garantem sua aplicabilidade como objeto constituidor de conhecimentos: a construção, a intervenção e a interferência. A construção é social e perpassa o processo de mediação que é construído socialmente e indica que ocorre nas interações entre mediadores, usuários com seus desejos e percepções, o que para o autor, é um dos pontos norteadores da mediação da 
informação. É esperado que a intervenção se manifeste na construção de sentidos entre mediador e usuário e seus imbricamentos, em que é possível intervir (por meio da mediação) entre um e outro, uns e outros e no próprio conhecimento a ser gerado. A intervenção que tem por objetivo a alteração de um estado para outro por meio de recursos, fontes e serviços de informação, é a própria mediação (SILVA, 2015).

Silva (2015) contextualiza que existem três outros pontos centrais norteadores do conceito de mediação na Ciência da Informação: 1) seu aspecto dinâmico e relacional; 2) a construção do conhecimento a partir da interação entre indivíduos e 3) a linha de investigação referente à interferência promovida pela prática mediacional. Na projeção da interferência, ponto defendido por Almeida Júnior $(2008,2009)$ e Silva (2015), a fundamentação social da mediação da informação vincula-se aos processos dialógicos, interacionistas, que estejam sem vínculo com hierarquias e procedimentos muito burocráticos e na perspectiva de que todos os envolvidos no processo de mediação necessitam reconhecer oportunidades de forma igualitária, assim como as diferenças e a autonomia de todos os envolvidos.

Já para Henriette Ferreira Gomes (2014, 2019), pesquisadora que se dedica a temática da mediação da informação há algum tempo, a interferência defendida primeiramente por Almeida Júnior (2009), também pode ser responsável pela manipulação da informação, ação antiética e fato complicador em tempos de fakenews, pós-verdade ou divulgação de dados sensíveis. Nesta constante, a autora tem atualizado o conceito, inclusive na aplicabilidade da mediação da informação em práticas que fortalecem e desenvolvem 0 protagonismo social tanto de bibliotecários mediadores, quanto de usuários que fornecem destino à informação recebida. Nessa esfera de raciocínio, a mediação da informação é elemento base e central no posicionamento da informação como aspecto fundante do protagonismo social, ou o que lhe dá sustentáculo. Com a mediação da informação alocada ao protagonismo social, cabe a usuários e profissionais da informação, o exercício da mediação e uso consciente da informação para transformar realidades subjugadas e em constante minoria. $\mathrm{Na}$ importante e atual visão de Gomes $(2014,2019)$, à mediação é atribuído o 
empoderamento da mudança, o enaltecer das minorias e o poderio das classes marginalizadas e em constante desvalorização.

O protagonismo social que levará a Ciência da Informação e seus pesquisadores e profissionais ao alcance de uma responsabilidade social (já amplamente debatida por Wersig e Neveling desde 1975) de fato concretizada na área, significa uma postura, um modo de resistência em todos os setores e dimensões da vida humana, a luta contra a discriminação, a rejeição, a defesa pelo diferente, o próprio apartheid social (GOMES, 2019) e outras manifestações necessárias em uma condição equitativa da sociedade. $O$ poder de transformação da informação é ressaltado por Gomes $(2014,2019)$ e Silva (2015) que acreditam que a mediação transforma e interfere o conhecimento existente e gerado nos indivíduos. Gomes (2019) defende que o protagonismo exige a tomada de decisão e de posição, o que se aplica sumariamente ao trabalho do bibliotecário mediador. A partir de suas escolhas informacionais tanto implícita quanto explicitamente, o bibliotecário e demais profissionais da informação podem lançar debates em manifestações sociais na defesa de direitos diversos de sua comunidade.

Nos últimos anos, outros autores internacionais contribuíram para uma compreensão detalhada dos desafios e da evolução do conceito de mediação acrescentando a noção de mediação online. Segundo Calenge e Boisvert (2015), a mediação é basicamente uma intervenção humana, uma história entre pessoas, um relacionamento entre profissionais e o público, uma atitude cívica, um lugar social. No entanto, Jean-Philippe Accart (2016) inclui a mediação online no debate, advertindo que nesse caso, não se reduz ao relacionamento direto, ao treinamento ou assistência ao usuário, mas o design de novos produtos de informação, marketing e monitoramento de serviços. Para este autor, a virtualização desse relacionamento, com a introdução de diferentes dispositivos técnicos ou processuais para facilitar a apropriação do conhecimento pelo público, coloca o usuário e o profissional da informação frente a frente (ACCART, 2016). A mediação da informação pode ser compreendida em diversas atividades do bibliotecário, tanto de forma direta (explícita) como indireta (implícita), de maneira presencial ou virtual, e sob diversas mídias e formatos 
informacionais.

\subsection{A MEdiaÇão da INFORMAÇão NAS AtividAdes do BiblioteCÁRIO}

Almeida Júnior (2009) evidencia que a mediação pode ocorrer de forma consciente ou inconsciente, o que se traduz ao fato do profissional mediar a informação em todas as ações que envolvem o seu trabalho. Por isso, a mediação da informação ocorrerá sempre que o bibliotecário realizar algum tipo de tratamento da informação. Isto significa que o profissional está envolvido em processos mediadores tanto de maneira implícita (indireta), quanto explícita (direta), ou ainda quando possui ou não consciência da ação de mediar.

A mediação ocorrerá de maneira indireta, ou como mediação implícita, em espaços e ambientes de informação diversos, sem a presença de usuário (ALMEIDA JÚNIOR, 2008). A mediação implícita é realizada no processamento técnico, como nas atividades de aquisição, descrição física ou temática e outras, com viés menos evidente, porém, existente. Esse tipo de ação mediadora se prospecta nas atividades-meio da instituição (ALMEIDA JÚNIOR, 2008; GOMES, 2014). A mediação direta ou explícita, muito mais evidente, transcorre na presença do usuário (mesmo que seja de forma virtual) (ALMEIDA JÚNIOR, 2008; GOMES, 2014). A mediação explícita costuma acompanhar a maioria das investigações publicadas a respeito dos processos mediadores encontrados na literatura científica da Ciência da Informação e representa igualmente, as atividades-fim da instituição.

Para além dos tipos de ações ou processos mediadores, ainda que não tenha consciência da ação, todo bibliotecário medeia informações e posições filosóficas, partidárias, e/ou culturais quando no manuseio e/ou tratamento da informação para seus usuários. A saber, para Gomes (2014, 2019), a mediação consciente da informação significa igualmente realizá-la com responsabilidade ética e social. De todo modo, alguns exemplos de mediação implícita são demonstrados como forma de facilitar a compreensão das ações mediadoras realizadas durante o trabalho do bibliotecário. As escolhas e posicionamentos do bibliotecário, durante a mediação implícita da informação, não são neutras (ALMEIDA JÚNIOR, 2008; VERGUEIRO, 1994) e esse é um quesito a ser 
compreendido pelo profissional que deseja realizar mediação ética da informação, como por exemplo, na: descrição temática da informação ou ainda, na indexação pois envolve a intenção do indexador quando na escolha de termos; aquisição, compra ou permuta de materiais que comporão o acervo da unidade de informação, e que são perscrutadas de posições pessoais, filosóficas, políticas e outras do profissional; escolha de linguagens controladas como tesauros, lista de cabeçalhos de assuntos e outros que podem por exemplo, projetar preconceitos/discriminações nos mais variados aspectos (étnico, religioso, orientação sexual/gênero.

Na mediação explícita da informação, os exemplos podem ser vistos nas seguintes ações: realização de entrevistas a usuários com suas necessidades informacionais no setor de referências; definição de termos de busca e na realização ou indicação de materiais para a dissolução de dúvidas e necessidades informacionais; divulgação de novas aquisições, de notícias, textos, indicações de leitura em estantes, websites, perfis em aplicativos e outros.

Tanto a mediação implícita quanto explícita da informação são desvendadas em diversas ações no trabalho do bibliotecário. Silva (2015) demonstra outros tipos de ações mediadoras no fazer do bibliotecário como a: Mediação técnica da informação: referente às ações de organização, e representação da informação como na elaboração de catálogos, interação por e-mail e/ou redes sociais relacionadas ao acervo tanto físico como virtual; Mediação pedagógica da informação: "[...] consiste na condução dos procedimentos e heurísticas a serem utilizadas no processo de mediação." (SILVA, 2015, p. 105). É necessário atenção nos estudos de usuários que abarquem o uso do acervo, das condições e dispositivos tecnológicos existentes, dos serviços ofertados, do quadro de funcionários e da unidade de informação em consonância com a comunidade que representa na autonomia informacional de seus indivíduos; Mediação institucional da informação: se constitui nos procedimentos de busca de recursos pelo profissional, como os financeiros, pessoais, de equipamentos tecnológicos, de acervo e outros, que possam promover interferências e a própria sustentabilidade (SILVA, 2015). 
Para Silva (2015), sob essas condições e tipologias mediadoras, a mediação da informação recebe papel central nos estudos da Ciência da Informação e em sua prática quanto a aspectos teórico-epistemológicos, tecnológicos, de gestão, de serviços, de estudos de usuários e outros assuntos da área. Portanto, o cuidado com a divulgação, compartilhamento e/ou questões que envolvam dados sensíveis, devem ser primários no atendimento e manuseio da informação seja em qualquer tipo de atividade realizada pelo bibliotecário, essencialmente o de mediar a informação, ação que ocorre em todas as tarefas exercidas pelo profissional em sua rotina de trabalho.

Diante desse cenário, a ALA (2008, Não paginado, tradução nossa) salienta a profissão do bibliotecário em seu trabalho e mediação ética da informação: "Distinguimos entre nossas convicções pessoais e nossas responsabilidades profissionais e não permitimos que nossas crenças pessoais interfiram na representação imparcial [do] acesso a nossos recursos de informação." Entretanto, com grande volume de informações pessoais e sensíveis existentes nas plataformas digitais, nem tudo pode ser divulgado ou compartilhado. Assim, os dados sensíveis são apresentados para a discussão de informações que, por motivos individuais ou coletivos, éticos ou legais, não podem compor o rol de conteúdos a serem mediados por bibliotecários, seja de forma implícita ou explícita, presencial ou virtual.

\section{DOS DADOS PESSOAIS AOS DADOS SENSÍVEIS}

Segundo a Lei 12.527/2011 - Lei de Acesso à Informação (LAI) - e a Lei 13.709/2018 - Lei Geral de Proteção de Dados Pessoais (LGPD) - um dado pessoal é a "[...] informação relacionada a pessoa natural identificada ou identificável." (BRASIL, 2011, 2018). De acordo com as Leis brasileiras, um dado pessoal é derivado de qualquer indivíduo ou pessoa natural (pessoa física), por dados e informações que possibilitem sua identificação de maneira unívoca. São exemplos de dados pessoais a numeração de documentos como o Registro Geral (RG), o Cadastro de Pessoa Física (CPF) e outros, além do nome próprio, nome dos pais e outras informações que possam identificar um indivíduo. Para Vignoli e Vechiato (2019), o valor de salários, faturas de cartões de crédito (e 
outras) de compras ou pagamentos, declaração de imposto de renda, acordos matrimoniais e outros documentos particulares, representam igualmente dados sensíveis.

Segundo a Lei da Proteção de Dados Pessoais de n. 57 de 26 de outubro de 1998 de Portugal, dado pessoal é "[...] qualquer informação, de qualquer natureza e independentemente do respectivo suporte, incluindo som e imagem, relativa a uma pessoa singular identificada ou identificável [...]." (PORTUGAL, 1998, Não paginado). Importante notar que nesse conceito, um dado pessoal pode ser compreendido sob qualquer tipo de suporte da informação. No Regulamento Geral sobre a Proteção de Dados (RGPD) - (2016) da União Europeia, o qual Portugal também é integrante, é considerada identificável toda pessoa cuja identidade pode determinar direta ou indiretamente mediante um identificador (como numeração de documentos pessoais).

O histórico de navegação e dados de conexão, por exemplo, demonstram dados atribuídos a sujeitos únicos, como os que navegam e usam seus computadores e dispositivos tecnológicos na rede. Inclui-se nessa assertiva, o que o indivíduo faz durante sua navegação na rede, como o que adquire, suas transações bancárias e principalmente, os assuntos de seu interesse e de pesquisa de forma geral que também representam seus dados sensíveis. Nesse cenário, mecanismos de buscas, como o Google, chamam esta ação de "personalização", e têm como objetivo propiciar a otimização semântica das buscas, uma vez que inclui a localização e o contexto do usuário. Assim, para Monteiro et al. (2017, p. 171):
A personalização se faz a partir da intenção de busca, que é inferida por meio das pragmáticas ou trilhas sígnicas semânticas deixadas pelo sujeito navegador, tanto no buscador quanto no ciberespaço. Hoje, é difícil fazer uma 'busca pura', isto é, sem algum tipo de personalização. O fato de estar 'logado', a cidade em que o usuário se localiza, a plataforma utilizada, o sistema operacional, a navegação, enfim, tudo é capturado por sistemas de busca. Isso quer dizer que as máquinas estão ouvindo o que milhões de pessoas falam, por meio de ferramentas linguísticas e estatísticas.

Para Rumbold e Pierscionek (2017), aplicativos, ferramentas, endereços de protocolos da internet, identificadores como tags de frequência de rádio entre outros itens aderentes ao meio digital e as tecnologias deixam vestígios que 
possibilitam o rastreamento e a identificação de indivíduos na rede. Esses resquícios de navegação quando combinados com identificadores únicos (como endereços de IP) e outras informações recebidas pelos servidores, são utilizados na criação de perfis de pessoas singulares, ou seja, na sua identificação.

Porquanto, dados pessoais são dados relacionados a um indivíduo de maneira unívoca, muito embora pessoas possuam nomes e sobrenomes idênticos, residam no mesmo endereço, ou tenham sua data de nascimento no mesmo dia e local. Acontece que um desses dados ou a somatória deles, torna possível a identificação de indivíduos, mas não demonstra suas preferências, costumes, crenças, aparência física, estado de saúde, entre outros tipos de dados compreendidos como sensíveis. Por isso, os dados sensíveis dissertam a respeito da vida privada, íntima e sigilosa de pessoas, instituições e objetos, fato que diferencia substancialmente dos dados pessoais.

A ANDS (2019) esclarece que dados sensíveis ou ainda confidenciais (vistos como equivalentes nesta pesquisa) são dados que podem ser utilizados para identificar um indivíduo, espécie, objeto ou local e que podem apresentar riscos de discriminação, dano ou atenção indesejada se divulgados. Conquanto, coaduna-se com a ANDS na formação dos dados sensíveis, para além de pessoas naturais e/ou jurídicas, o que se estende a objetos, documentos, patentes, entre outros tipos.

A National Science Board (NSB) - (2005), juntamente com Briney (2015), elencam outros tipos de dados com acesso limitado ou totalmente restritos que podem ser categorizados como dados sensíveis, quais sejam: dados de segurança nacional, de inteligência, de atividades militares, de decisões políticas, de segredos comerciais ou empresariais, de proteção de espécies raras, ameaçadas ou em perigo e de processos legais como dados referentes a ações judiciais e outros que não devem ser divulgados. Características físicas humanas como cor ou tipo de cabelo ou pele, uso de piercings ou tatuagens, ou estado de saúde e demais informações individuais são classificadas como dados sensíveis, pois podem levar indivíduos a discriminações e outros tipos de transtornos em ambientes específicos como o de trabalho, acentuam Rumbold e Pierscionek (2017). Importante destacar que a divulgação de imagens 
humanas sem a permissão de seus indivíduos, além de ser crime, remete a mais um tipo de dado sensível. Briney (2015) evidencia dados sensíveis decorrem também de pesquisas, como as científicas, governamentais, empresariais e/ou comerciais, entre outras.

No RGPD (2016), dados sensíveis são denominados como dados acerca de saúde, origem racial ou étnica, opiniões políticas e orientação sexual ou informações múltiplas que necessitem de proteção especial, ou ainda, de sigilo. Dados médicos ou de saúde são sensíveis por natureza e classificados por Chassang (2017) no conjunto de dados que respondem à saúde física ou mental, exames ou substâncias corporais, amostras biológicas, histórico ou tratamento clínico ou estado fisiológico/biomédico do titular. Dados biométricos, genéticos, imagens faciais ou dados dactiloscópicos (identificação humana por meio de impressões digitais) são considerados como dados de saúde privados e por isso, sensíveis.

De modo sumário, os dados sensíveis são dados relacionados a pessoas naturais, jurídicas e a objetos, que se cruzam com dados de cunho pessoal, médicos, científicos, empresariais, jurídicos, ecológicos e outros, sob diversos tipos de informações privadas respaldadas por leis de proteção à privacidade e por questões éticas. Dados sensíveis não devem ser divulgados, e todo bibliotecário, deve conhecer essa especificidade de dados e seus entornos legais e éticos para a mediação da informação. Como nem todos os dados são passíveis de mediação, a próxima seção tratará de explicitar alguns dispositivos éticos e legais de proteção à privacidade de dados sensíveis.

\section{DISPOSITIVOS LEGAIS E ÉTICOS DE PROTEÇÃO DE DADOS SENSÍVEIS}

No cotidiano, é comum que as pessoas utilizem e forneçam seus dados pessoais para inúmeras finalidades, principalmente aquelas que resultam em compras pela internet, e também em estabelecimentos comerciais físicos. $O$ fornecimento de dados pessoais ocorre na realização de cadastros solicitados por empresas, no pagamento da compra realizada tanto de forma presencial quanto online ou mesmo na autorização de fotografia para compor o banco de 
cadastro da empresa ou edifício comercial que se deseja adentrar. Ações como essas resultam no fornecimento voluntário de dados pessoais e sensíveis por meio do próprio indivíduo. A disponibilização de dados pessoais e sensíveis a terceiros por livre consentimento ocorre diariamente sem que indivíduos percebam que estão fornecendo seus dados.

A Constituição Federal de 1988 já refletia preocupação com a inviolabilidade dos dados e informações pessoais dos indivíduos quando fora elaborada. Por isso, o clássico Art. 5ำ da Constituição Federal relata que:

Todos os cidadãos são iguais perante a lei, sem distinção de qualquer natureza, seja de gênero, raça, sexualidade e decisão religiosa, garantindo-se aos brasileiros e aos estrangeiros residentes no País a inviolabilidade do direito à vida, à liberdade, à igualdade, à segurança e à propriedade [...]. (BRASIL, 1988, não paginado).

A Constituição Federal demonstra conduta base para qualquer tipo de atendimento por profissionais de áreas afins, que devem primar antes de qualquer situação, pelo tratamento de todo indivíduo da mesma maneira (não se discutirá, neste artigo, a igualdade material e formal, que têm distinções e implicações pragmáticas significativas na interpretação do artigo supracitado). 0 artigo $5^{\circ}$ torna claro que a todos é garantido o direito à segurança e privacidade, o que se estende a seus dados e informações privadas e confidenciais - aos seus dados sensíveis. Os incisos X e XIV da Carta Magna são pertinentes nesta discussão:

\begin{abstract}
X - são invioláveis a intimidade, a vida privada, a honra e a imagem das pessoas, assegurado o direito a indenização pelo dano material ou moral decorrente de sua violação [...]

XIV - é assegurado a todos o acesso à informação e resguardado o sigilo da fonte, quando necessário ao exercício profissional [...]. (BRASIL, 1988, não paginado).
\end{abstract}

Os incisos evidenciam o direito de inviolabilidade à vida privada e seus desdobramentos, assim como é garantido que o profissional que tenha acesso a esses dados zele por sua segurança. É o que cabe aos bibliotecários na compreensão do art. $5^{\circ}$ da Constituição como premissa essencial para atuar em sociedade e a serviço dela, essencialmente na mediação da informação no contexto dos dados sensíveis. 
A Lei de Acesso à Informação - LAl, que fora desenvolvida para tornar informações públicas de acesso livre à população, explica aos cidadãos seus direitos a proteção de seus dados:

Art. 6o Cabe aos órgãos e entidades do poder público, observadas as normas e procedimentos específicos aplicáveis, assegurar a [...] III - proteção da informação sigilosa e da informação pessoal, observada a sua disponibilidade, autenticidade, integridade e eventual restrição de acesso. (BRASIL, 2011, não paginado).

Apesar de ter aplicabilidade principalmente em órgãos públicos, a LAI assegura o direito à privacidade de dados e informações de civis, quando em contato com órgãos distintos. Neste caso, poder-se-á aplicar o que consta no dispositivo legal em unidades de informação públicas, como as bibliotecas, centros de documentação e outros ambientes de atuação do bibliotecário e profissionais da informação. No art. 6ำ da LAl é indicado que os órgãos e entidades do poder público deverão observar normas e procedimentos aplicáveis a proteção de informações sigilosas, o que caberá também a biblioteca ou unidade de informação, essencialmente quando pública. Contudo, concerne às entidades assegurar que exista a:

II - proteção da informação, garantindo-se sua disponibilidade, autenticidade e integridade; [...] III - proteção da informação sigilosa e da informação pessoal, observada a sua disponibilidade, autenticidade, integridade e eventual restrição de acesso. (BRASIL, 2011, não paginado).

Nesse sentido, o bibliotecário deve se prontificar a apreciação e aplicação dos parágrafos da Lei em sua rotina de trabalho e no ato de mediar a informação, seja de forma direta ou indireta, presencial ou virtual, para um indivíduo ou para grupos. No art. 25 da LAl está previsto que o Estado deverá controlar o acesso e a divulgação de informações sigilosas e/ou sensíveis e que "§ $2^{\circ} \mathrm{O}$ acesso à informação classificada como sigilosa cria a obrigação para aquele que a obteve de resguardar o sigilo [...]" (BRASIL, 2011, Não paginado) que poderá ser o bibliotecário. Constituirá ainda como conduta inapropriada e ilícita disposta no art. 32 "IV - divulgar ou permitir a divulgação ou acessar ou permitir acesso indevido à informação sigilosa ou informação pessoal." (BRASIL, 2011, Não paginado). 
Na Lei Geral de Proteção de Dados Pessoais - LGPD, dispositivo criado exclusivamente para a proteção de dados pessoais (e sensíveis) da população brasileira, é evidenciado que o tratamento de dados pessoais ou sensíveis somente poderá ocorrer: "I - quando o titular ou seu responsável legal consentir, de forma específica e destacada, para finalidades específicas [...]" (BRASIL, 2018) ou em casos em que a justiça julgue necessário, sendo vedado o vício de consentimento. No que a Lei n. 67 de 1998 de Portugal declara como impedido de tratamento aos dados sensíveis, considera-se como sua definição: "[...] convicções filosóficas ou políticas, filiação partidária ou sindical, fé religiosa, vida privada e origem racial ou étnica, bem como o tratamento de dados relativos à saúde e à vida sexual, incluindo os dados genéticos." (PORTUGAL, 1998, Não paginado). Segundo o art. 17 "Toda pessoa natural tem assegurada a titularidade de seus dados pessoais e garantidos os direitos fundamentais de liberdade, de intimidade e de privacidade, nos termos desta Lei." (BRASIL, 2018, Não paginado). Conforme destacado na LGPD e em outros dispositivos legais, como a Constituição Federal e a LAI, todo cidadão tem direito à privacidade resguardada por lei. Foi nesta constante que o Poder Legislativo brasileiro elaborou a sua primeira lei específica de proteção de dados pessoais que se estende aos dados sensíveis. Conforme destacam Calheiros e Takada (2015, p. 12) "O direito necessitou remodelar o entendimento, a subsunção do fato à norma, mas não o bem jurídico a ser resguardado [...]" para atender as novas demandas jurídicas e sociais de atenção à privacidade dos indivíduos. A saber, a União Europeia discute e possui leis e diretrizes a esse respeito desde a década de 1980.

Ao se referir às responsabilidades éticas do bibliotecário, a ALA (2008, Não paginado, tradução nossa) profere que "Temos um grau significativo de influência e controle na seleção, organização, preservação e disseminação de informações." Em consonância à afirmação da instituição, que é sumidade nas atividades biblioteconômicas do mundo todo, é esperado que ao bibliotecário caiba o pleno entendimento das possibilidades informativas que seu trabalho pode prover. Com isso, o bibliotecário acaba por possuir influência e controle sobre a informação que manuseia, trata e medeia. Diante dessa prerrogativa, de 
acordo com o Código de Ética da ALA (2008, Não paginado, tradução nossa) “III. Protegemos o direito de cada usuário das bibliotecas de manter sua privacidade e confidencialidade em relação às informações consultadas ou recebidas e aos recursos consultados, emprestados, adquiridos ou transmitidos."

Como instrumento específico e tangenciador das práticas do bibliotecário, no Brasil, o Código de Ética e Deontologia do Bibliotecário aprovado na Lei no 4.084, de 30 de junho de 1962, e pelo Decreto n. 56.725 de 16 de agosto de 1965, atualizado na Resolução CFB № 207/2018, explica que um dos deveres do profissional é "[...] guardar sigilo no desempenho de suas atividades, quando o assunto assim exigir." (CONSELHO FEDERAL DE BIBLIOTECONOMIA, 2018, Não paginado). Em relação aos usuários atendidos pelo bibliotecário, o Código de Deontologia e Ética em seu $§ 3^{\circ}$ explica que compete ao profissional: "d) assumir responsabilidades pelas informações fornecidas, de acordo com os preceitos do Código Civil, do Código de Defesa do Consumidor e da Lei de Acesso à informação vigentes [...]." (CONSELHO FEDERAL DE BIBLIOTECONOMIA, 2018, Não paginado). Inclui-se neste conjunto legislativo de recomendações do Conselho Federal de Biblioteconomia (CFB) quanto à segurança e privacidade de dados alheios, a LGPD, instrumento ainda não existente na publicação da atualização do Código de Ética e Deontologia do Bibliotecário de 2018.

Para tanto, durante o exercício da profissão, fica proibido ao bibliotecário, violar o sigilo profissional quando se tratar ou for portador de informações confidenciais (CONSELHO FEDERAL DE BIBLIOTECONOMIA, 2018). Nesse sentido, são consideradas como ações ético-disciplinares passíveis de penalidades, como disposto no parágrafo "I - violar o sigilo profissional de fatos que tenha tomado conhecimento no exercício da profissão, com exceção daqueles presentes em lei que exigem comunicação, denúncia ou relato a quem de direito." (CONSELHO FEDERAL DE BIBLIOTECONOMIA, 2018, Não paginado).

É salutar ressaltar que no contexto da Ciência da Informação, o bibliotecário deve estar atento sobre as principais ações expressas em leis e no Código de Ética do Bibliotecário, tanto do Brasil quanto da ALA, inclusive, no ato 
de mediar a informação para uma comunidade de usuários. $\mathrm{O}$ ato de mediar a informação é muito comum em bibliotecas e unidades de informação e a responsabilidade do bibliotecário em conhecer conjuntos legislativos e éticos a serem aplicados no seu trabalho, tornam-se desafios aos profissionais que devem primar pelo acesso à informação de qualidade.

Em seu conceito de mediação da informação, Silva (2015) cita as referências feitas a normas/regras que remetem às premissas estabelecidas institucionalmente e que devem ser cumpridas tanto por profissionais da informação quanto por usuários. Gomes (2014, 2019), por outro lado, informa que nas ações mediadoras com enfoque na dimensão ética da informação, a mediação deve ser praticada munida de consciência e competência do profissional para que as interferências ocorram sem manipulações. É necessário também que a dimensão ética garanta o diálogo, a escuta, o acolhimento e acesso direto à diversidade, ao pensamento livre e à mediação sem censuras ou tratamento desigual, sumariza a autora. Espera-se igualmente que no comportamento ético-moral do bibliotecário na mediação da informação, aspectos como o arranjo do acervo seja realizado de maneira acessível, sem nenhum tipo de censuras ou estigmas. Partindo da premissa de que os usuários fornecem algumas informações pessoais cada vez que se valem de serviços da biblioteca (KLIENEFELTER, 2017), o Quadro 1 objetiva demonstrar algumas formas de acesso a dados pessoais e sensíveis pelo bibliotecário.

Quadro 1 - Dados pessoais e sensíveis em unidades de informação

\begin{tabular}{l|l|l}
\hline \multicolumn{1}{c|}{ Serviço/produto } & \multicolumn{1}{|c}{$\begin{array}{c}\text { Dados pessoais } \\
\text { disponibilizados }\end{array}$} & \multicolumn{1}{c}{$\begin{array}{c}\text { Dados sensíveis } \\
\text { encontrados }\end{array}$} \\
\hline Empréstimos diversos & $\begin{array}{l}\text { Dados de cadastro, nome próprio, } \\
\text { identificação por carteirinha da } \\
\text { biblioteca, número de documentos } \\
\text { pessoais como RG, CPF, e-mail, } \\
\text { endereço, telefone. }\end{array}$ & $\begin{array}{l}\text { Dados que podem demonstrar } \\
\text { preferências ou interesses } \\
\text { particulares de cada indivíduo, } \\
\text { como seus comportamentos } \\
\text { de leitura. Sua imagem em } \\
\text { fotografia. }\end{array}$ \\
\hline $\begin{array}{l}\text { Busca por materiais no } \\
\text { catálogo eletrônico e/ou } \\
\text { online da unidade de } \\
\text { informação }\end{array}$ & $\begin{array}{l}\text { E-mails, número de identificação } \\
\text { como número de carteirinha, de } \\
\text { matrícula, login e senha; } \\
\text { IP da máquina ou dispositivo } \\
\text { eletrônico conectado a internet. }\end{array}$ & $\begin{array}{l}\text { É possível identificar os termos } \\
\text { e/ou palavras-chave utilizadas } \\
\text { na pesquisa que demonstram } \\
\text { assuntos pesquisados em } \\
\text { suas particularidades. }\end{array}$ \\
\hline
\end{tabular}




\begin{tabular}{l|l|l}
\hline $\begin{array}{l}\text { Solicitação de busca } \\
\text { bibliográfica } \\
\text { especializada via } \\
\text { COMUT ou não }\end{array}$ & $\begin{array}{l}\text { Nome próprio, contato via e-mail, } \\
\text { telefone, ocupação institucional, } \\
\text { nível de especialização na } \\
\text { instituição. }\end{array}$ & $\begin{array}{l}\text { Ao criar perfil de pessoa em } \\
\text { particular, cria-se registro de } \\
\text { interesses do indivíduo com } \\
\text { suas preferências como de } \\
\text { leitura ou pesquisa. }\end{array}$ \\
\hline $\begin{array}{l}\text { Manifestações e } \\
\text { solicitações públicas de } \\
\text { informação, opiniões, } \\
\text { postsdiversos }\end{array}$ & $\begin{array}{l}\text { Nome próprio e/ou username na } \\
\text { rede social, e-mail, telefone, entre } \\
\text { outros. }\end{array}$ & $\begin{array}{l}\text { Divulgação de imagens sem } \\
\text { consentimento por escrito do } \\
\text { usuário, opiniões e } \\
\text { manifestações diversas por } \\
\text { escrito que comprovam } \\
\text { preferências, interesses, } \\
\text { conflitos, posicionamentos } \\
\text { políticos, filosóficos e outros } \\
\text { como nas redes sociais. }\end{array}$ \\
\hline
\end{tabular}

Fonte: Elaborado pelos autores baseado em Klienefelter (2017).

Como é passível de observação, com a finalidade de buscar eficiência e personalizar serviços, os sistemas de bibliotecas produzem bancos de dados com inúmeras formas de acesso a dados pessoais e sensíveis de seus usuários. Ao promover a ligação de um registro de usuário com um item, cria-se uma trilha eletrônica que possibilita o rastreamento de informações. A partir das potencialidades que informações oferecem, um longo caminho de danos à privacidade pode ser percorrido, desde o manuseio deliberado e incorreto de dados pessoais, passando pelo uso inapropriado de informações fora do contexto primeiro, ao monitoramento de suas preferências e hábitos de leitura e ao rastreamento do comportamento do usuário de maneiras cada vez mais sofisticadas (KLIENEFELTER, 2017).

No entanto, os bibliotecários e demais profissionais da informação possuem diversos dispositivos éticos e legais a serem compreendidos e aplicados no decorrer de sua rotina diária de trabalho. A não observância dessas normas e legislações, além das existentes a cada unidade de informação e/ou comunidade, implica sobremaneira, na indução inapropriada da profissão e indubitavelmente na mediação da informação realizada de má qualidade e com traços antiéticos. Como forma de esclarecimentos, os dados sensíveis são conceituados e contextualizados para que o bibliotecário compreenda sua definição e aplicação como um tipo de informação que não deve, não pode e que naturalmente não necessita ser mediada, principalmente quando se trata de dados sensíveis de pessoas naturais, que podem ser seus próprios usuários. No 
tocante às buscas feitas nos mecanismos, cabe ao usuário a verificação da configuração de privacidade, sendo possível a sua edição, para indicar quais informações pessoais serão compartilhadas ou tornadas públicas. Por isso, a mediação da informação necessita ser muito consciente.

\section{CONSIDERAÇÕES FINAIS}

O presente estudo apresentou uma análise das nuances acerca do conceito e da prática da mediação da informação, como definida pela Ciência da Informação, essencialmente em suas formas implícitas e explícitas, como mecanismo de interferência entre a informação, o bibliotecário e o usuário, e como insumo para a construção de conhecimento e protagonismo social.

As reflexões apresentadas e os dispositivos legais e éticos demonstram a importância de se refletir não somente sobre a mediação da informação, mas acerca de todas as atividades realizadas pelo bibliotecário em prol de seus usuários, seja para o acesso à informação, ou para sua proteção, no caso de dados sensíveis. Cada vez mais os sistemas de informação e serviços oferecidos pela biblioteca coletam dados pessoais dos usuários que são processados e armazenados em bancos de dados. A personificação dos serviços oferecidos pela biblioteca, a exigência do uso de senha e realização de login para realização de pesquisas ou empréstimos entre bibliotecas, na recuperação de documentos, em serviços de alerta, possibilitam o rastreamento do comportamento do usuário pelas trilhas eletrônicas deixadas.

Nesse sentido e em resposta aos questionamentos de Garcia (1992), nem todas as informações podem ser do conhecimento de todos, pois os dados sensíveis não devem ser divulgados. Existem informações sigilosas, como as de cunho sensível, o que exige do bibliotecário o pleno conhecimento das leis e normas éticas e legais para o manuseio de tratamento deste tipo de informação.

Destaca-se que a mediação da informação, para além do acesso à informação, deve considerar também a proteção aos dados dos usuários pelo bibliotecário e sua responsabilidade nesse sentido. Por fim, a partir dessa análise percebe-se que a mediação da informação envolve responsabilidades e oportunidades que circundam o papel ético e consciente do bibliotecário em sua 
rotina diversa de trabalho, e possibilita sobremaneira, o protagonismo social ético e contraproducente.

\section{REFERÊNCIAS}

ACCART, J. La médiation à l'heure du numérique. Éditions du Cercle de la librairie, 2016.

ALMEIDA JÚNIOR, O. F. de. Mediação da informação e múltiplas linguagens. Tendências da Pesquisa Brasileira em Ciência da Informação, Brasília, DF, v. 2, n. 1, p. 89-103, jan./dez. 2009. Disponível em: http://www.brapci.inf.br/index.php/article/view/0000007770/7f7019d537ab408a1 0196b4d752bb50d. Acesso em: 02 jun. 2020.

ALMEIDA JÚNIOR, O. F. de. Mediação da informação e múltiplas linguagens. In: ENCONTRO NACIONAL DE CIÉNCIA DA INFORMAÇÃO (ENANCIB), 9., São Paulo, 2008. Anais [...]. São Paulo: Universidade de São Paulo, 2008. p. 01-14.

AMERICAN LIBRARY ASSOCIATION (ALA). Code of ethics of the American Library Association. [Adotado na reunião de inverno de 1939 pelo Conselho da ALA; alterado em 30 de junho de 1981; 28 de junho de 1995; e 22 de janeiro de 2008].

AUSTRALIAN NATIONAL DATA SERVICES (ANDS). 2019. Disponível em: https://www.ands.org.aul. Acesso em: 18 maio. 2020.

BELLUZZO, R. C. B.; SANTOS, C. A. dos; ALMEIDA JÚNIOR, O. F. de. A competência em informação e sua avaliação sob a ótica da mediação da informação: reflexões e aproximações teóricas. Informação \& Informação, Londrina, PR, v. 19, n. 2, p. 60-77, maio/ago. 2014. DOI: 10.5433/1981-8920. Disponível em: http:www.uel.br/revistas/informacao/. Acesso em: 23 jun. 2020.

BERNI, R. I. G. Mediação: o conceito vygotskyano e suas implicações na prática pedagógica. In: SIMPÓSIO NACIONAL DE LETRAS E LINGUÍSTICA; SIMPÓSIO INTERNACIONAL DE LETRAS E LINGUÍSTICA, 9., 1., Uberlândia, MG, 2006. Anais [...]. Uberlândia-MG: UFU, 2006. Disponível em:

http://www.filologia.org.br/ileel/artigos/artigo_334.pdf. Acesso em: 21 jun. 2020.

BORTOLIN, S.; CERVANTES, B. M. N. A mediação da informação em múltiplas abordagens [editorial]. Informação \& Informação, Londrina, PR, v. 19, n. 2, maio/ago. 2014. DOI: 10.5433/1981-8920. Disponível em:

http:www.uel.br/revistas/informacao/. Acesso em: 23 jun. 2020.

BRASIL. [Constituição (1988)]. Constituição da República Federativa do

Brasil de 1988. Brasília-DF: Presidência da República, 1988. 
BRASIL. Lei n.o 12.527, de 18 de novembro de 2011. [Lei de Acesso à Informação (LAI)]. Regula o acesso a informações previsto no inciso XXXIII do art. 5으, no inciso II do $\S 3^{\circ}$ do art. 37 e no $\S 2^{\circ}$ do art. 216 da Constituição Federal; altera a Lei oㅜ 8.112, de 11 de dezembro de 1990; revoga a Lei oㅜ 11.111, de 5 de maio de 2005, e dispositivos da Lei no 8.159 , de 8 de janeiro de 1991; e dá outras providências. Brasília: Presidência da República, 2011.

BRASIL. Lei n.o 13.709, de 15 de agosto de 2018. [Lei Geral de Proteção de Dados Pessoais (LGPD)]. Dispõe sobre a proteção de dados pessoais e altera Lei n ${ }^{\circ} 12.965$ de 23 de abril de 2014. [Marco Civil Internet]. Brasília: Presidência da República, 2018.

BRINEY, K. Data management for researchers: organize, maintain and share your data for research success. Exeter, UK: Pelagic Publishing, 2015. (Research Skills Series).

CALENGE, B.; BOISVERT, D. Les bibliothèques et lamédiation des connaissances. Documentation et Bibliothèques, Canadá, v. 61, n. 4, p. 188189, 2015.

CALHEIROS, T. da C.; TAKADA, T. A. Reflexões sobre a privacidade na Sociedade da informação. Informação \& Informação, Londrina, PR, v. 4, n. 1, p. 120-134, jan./jun. 2015.DOI: 10.5433/2317-4390. Disponível em: http://www.uel.br/revistas/uel/index.php/infoprof/article/view/22564/17209. Acesso em: 02 dez. 2020.

CHASSANG, G. The impact of the EU general data protection regulation on scientific research. Ecancer Medical science, Reino Unido, v. 11, n. 709, 2017.

CONSELHO FEDERAL DE BIBLIOTECONOMIA (CFB). Código de Ética e Deontologia do Bibliotecário. Resolução CFB no 207/2018. Aprova o Código de Ética e Deontologia do Bibliotecário brasileiro, que fixa as normas orientadoras de conduta no exercício de suas atividades profissionais. Brasília: Diário Oficial da União de 09/11/2018, Seção 1, págs. 155 e 156.

FREIRE, I. M.; FREIRE, G. Mediação na Ciência da Informação [editorial]. Ciência da Informação, Brasília, DF, v. 43 n. 2, maio/ago. 2014. Disponível em: http://revista.ibict.br/ciinf/issue/view/110/showToc. Acesso em: 24 jun. 2020.

GARCIA, J. C. R. Bibliotecário: informar tudo a todos? Informação \& Sociedade: Estudos, João Pessoa-PB, v. 2, n. 1, p. 50-54, jan./dez. 1992. Disponível em:

https://periodicos.ufpb.br/ojs2/index.php/ies/article/view/44/1351. Acesso em: 25 maio 2020.

GOMES, H. F. Protagonismo social e mediação da informação. Logeion:

Filosofia da Informação, Rio de Janeiro, v. 5, n. 2, p. 10-21, mar./ago. 2019. 
DOI: https://doi.org/10.21728/logeion.2019v5n2.p10-21. Disponível em: http://revista.ibict.br/fiinf/article/view/4644/4046. Acesso em: 14 jun. 2020.

GOMES, H. F. A dimensão dialógica, estética, formativa e ética da mediação da informação. Informação \& Informação, Londrina, PR, v. 19, n. 2, p. 46-59, maio/ago. 2014. DOI: 10.5433/1981-8920.2014v19n2p46. Disponível em: http:www.uel.br/revistas/informação. Acesso em: 17 jun. 2020.

HOUAISS, A.; VILLAR, M. de S. Dicionário Houaiss da Língua Portuguesa. Rio de Janeiro: Objetiva, 2001.

JAPIASSÚ, H.; MARCONDES, D. Dicionário básico de Filosofia. 3. ed. Rio de Janeiro: Jorge Zahar, 1998.

KLIENEFELTER, A. Privacy and library public services: or, I know what you read last summer. Legal Reference Services Quarterly, EUA, v. 26, n.1/2, p. 1-31, set. 2017.

LIMA, Í. E. P. de et al. Uma experiência da Psicologia com mediação de conflitos: estágio em Psicologia e processos de gestão. Revista de Psicologia, Fortaleza, CE, v. 8 n. 2, p. 129-135, jul./dez. 2017. Disponível em: http://www.periodicos.ufc.br/psicologiaufc/article/view/19280. Acesso em: 21 jun. 2020.

MONTEIRO, S. D.et al. Sistemas de recuperação da informação e o conceito de relevância nos mecanismos de busca: semântica e significação. Encontros Bibli, Florianópolis, SC, v. 22, n. 50, p. 161-175, 2017.

NATIONAL SCIENCE BOARD (NSB). Long-lived digital data collections: enabling research and education in the21stcentury. National Science Foundation, Sept. 2005.

ORTEGA Y GASSET, J. Misión del bibliotecario. Edición conmemorativa del 50 aniversario luctuoso del autor y de la celebracióndel Día Nacional del Bibliotecario. Prólogo de Jesús Sánchez Lambás. México, Madrid: Consejo Nacional para la cultura y las artes - Dirección Geral de bibliotecas; Fundación José Ortega y Gasset, 2005. (Colección Biblioteca del Bibliotecario).

PORTUGAL. Lei no 67, de 26 de outubro de 1998. Lei de protecção de dados pessoais. Transpõe para a ordem jurídica portuguesa a directiva 95/46/CE, do Parlamento Europeu e do Conselho, de 24 de outubro de 1995, relativa à protecção das pessoas singulares no que diz respeito ao tratamento dos dados pessoais e à livre circulação desses dados. Assembleia da República: Portugal, 1998.

RUMBOLD, J. M. M.; PIERSCIONEK, B. K. What are data?: a categorization of the data sensitivity spectrum. Big Data Research, EUA, n. 12, p. 49-59. 2017.

RUSS, J. Dicionário de Filosofia: os conceitos: filósofos: 1980: citações. São Paulo: Scipione, 2003. 
SÁNCHEZ LAMBÁS, J. Prólogo. In: ORTEGA Y GASSET, J. Misión del bibliotecario. Edición conmemorativa del 50 aniversario luctuoso del autor y de la celebración del Día Nacional del Bibliotecario. México, Madrid: Consejo Nacional para la cultura y las artes - Dirección Geral de bibliotecas; Fundación José Ortega y Gasset, 2005. (Colección Biblioteca del Bibliotecario).

SANTAELLA, L. A teoria geral dos signos: como as linguagens significam as coisas. São Paulo: Pioneira, 2004.

SILVA, J. L. C. Percepções conceituais sobre mediação da informação. InCID: Revista de Ciência da Informação e Documentação, Ribeirão Preto, SP, v. 6, n. 1, p. 93-108, mar./ago. 2015. DOI: 10.11606/issn.2178-2075.v6i1p93-108. Disponível em: http://www.periodicos.usp.br/incid/article/view/89731/96288. Acesso em: 15 jun. 2020.

UNIÃO EUROPEIA (UE). Regulamento Geral sobre a Proteção de Dados (RGPD). Regulamento (UE) 2016/679 do Parlamento Europeu e do conselho de 27 de abril de 2016 relativo à proteção das pessoas singulares no que diz respeito ao tratamento de dados pessoais e à livre circulação desses dados e que revoga a Diretiva 95/46/CE, 2016.

VERGUEIRO, W. C. S. Ética profissional versus ética social: uma abordagem sobre os mitos da biblioteconomia. Palavra-chave, São Paulo, n. 8, 1994, p. 811.

VIGNOLI, R. G.; VECHIATO, F. L. Dados pessoais, dados sensíveis e dados pessoais sensíveis: um contributo conceitual para a Ciência da Informação. In: FARIAS, G. B. de; FARIAS, M. G. G. (org.). Competências e mediação da informação: percepções dialógicas entre ambientes abertos e científicos. São Paulo: Abecin, 2019. 305p. (Coleção Estudos ABECIN; 09).

\title{
MEDIATION OF INFORMATION AND THE PROTECTION OF PRIVACY AND SENSITIVE DATA BY LIBRARIANS
}

\begin{abstract}
Introduction: It emphasizes the role of the librarian in the protection and confidentiality of information that cannot, should not or does not need to be mediated. To this end, it contextualizes the mediation of information and presents legal environments, based on the Federal Constitutionof Brazil, the Access to Information Law, the Personal Data Protection Law, and ethical environments based on the Code o fEthics and Deontology of the Librarian in Braziland in the American Library Association's Code of Ethics, in the accuracy and observance of the necessary conduct in order not to mediate users' confidential and sensitive data or information. Objective: to discuss about sensitive data in the mediation of information, either in the implicit (in technical processing of information) or explicit (in direct servisse to users) forms, and in access to users' sensitive data in units of information. Methodology: As a methodological procedure, it is a literature search with a qualitative approach. Results: It is verified that sensitive data should not be disclosed and that, therefore, not all information can be shared and
\end{abstract}


mediated. Conclusions: It is expected to contribute to new research and discussions concerning the subject and mainly to other studies in the constructs of the literature on the mediation of information combined with sensitive data.

Descriptors: Mediation of information. Privacy in the Mediation of Information. Sensitive Data. Sensitive Data in Information Mediation. Ethics and Information Mediation.

\title{
MEDIACIÓN DE LA INFORMACIÓN Y PROTECCIÓN DE PRIVACIDAD DE LOS DATOS SENSIBLES POR BIBLIOTECÓLOGO
}

\begin{abstract}
RESUMEN
Introducción: Destaca el papel del bibliotecólogo em laprotección y sigilo de informaciones que no pueden, no deben o que no necesitan ser mediadas. Para eso, contextualiza la mediación de la información y presenta ambiências legales, basadas em la Constitución Federal de Brasil e en código de Ética de la American Library Association, en la precisión y cumplimiento de conductas necesarias para no mediar datos o informaciones sigilosas y sensibles de los usuarios. Objectivo: El objectivo de investigaciónes discutir acerca de los datos sensibles en la mediación de la información, sea de manera implícita (en el procesamiento técnico de la información) ou en la explícita ( en lo atendimento directo a los usuarios), y en e lacceso a datos sensibles de usuários en las unidad de información. Metodología: Como procedimiento metodológico, esta es una investigación bibliográfica com enfoque qualitativo. Resultados: Parece que no se deben divulgar datos confidenciales y, por lo tanto, no toda la información está sujeta a intercambio y mediación. Conclusiones: Se espera que contribuya con nueva sinvestigaciones y discusiones acerca de la temática y principalmente com otros estudios de la literatura de la mediación de la información aliada a los datos sensibles.
\end{abstract}

Descriptores: Mediación de lainformación. Privacidad em la Mediación de la Información. Datos Sensibles. Datos Sensibles em la Mediación de la Información. Ética y Mediación de la Información.

Recebido em: 17.07 .2020

Aceito em: 14.12 .2020 